\title{
ANALISIS PEMASARAN PADA AGROINDUSTRI TEMPE DI KOTA PALANGKA RAYA
}

\author{
MARKETING ANALYSIS AT TEMPE AGROINDUSTRY \\ IN PALANGKA RAYA CITY
}

\author{
${ }^{1}$ Hamim Thohari, ${ }^{2}$ Jhon Wardie, ${ }^{3}$ Revi Sunaryati \\ ${ }^{1}$ Alumnus Program Studi Agribisnis, Fakultas Pertanian, Universitas Palangka Raya \\ ${ }^{2,3}$ Staf Pengajar Program Studi Agribisnis, Fakultas Pertanian, Universitas Palangka Raya \\ email: jwardie@agb.upr.ac.id
}

\begin{abstract}
ABSTRAK
Penelitian ini dilaksanakan di Kota Palangka Raya. Pemilihan lokasi penelitian dilakukan secara sengaja (purposive sampling) dengan pertimbangan bahwa sebagai ibukota Provinsi Kalimantan Tengah, di Kota Palangka raya banyak antivitas dan menjadi sentra produksi agroindustri tempe. Penentuan responden agroindustri tempe dilakukan dengan menggunakan metode sensus (sensus sampling), yaitu dengan mengambil semua pengusaha agroindustri tempe (16 pengusaha) yang ada di Kota Palangka Raya. Selanjutnya penentuan lembaga pemasaran tempe yang meliputi pedagang besar dan pedagang pengecer dilakukan dengan metode penelusuran (snowball sampling). Data yang dikumpulkan dalam penelitian ini adalah data primer dan data sekunder. Pemasaran tempe di Kota Palangka Raya terdiri dari tiga saluran pemasaran dan lembaga pemasaran yang terlibat adalah pedagang besar dan pedagang pengecer. Total biaya pemasaran tempe per bungkus pada pola saluran pemasaran I, II dan III masing-masing sebesar Rp. 0,-, Rp. 500,- dan Rp. 1.000,-, serta Rp. 1.200,-. Total marjin pemasaran tempe per bungkus pada pola saluran pemasaran I sebesar Rp. 900,- untuk ukuran kecil, Rp. 1.100,- untuk ukuran sedang dan Rp. 1.210,- untuk ukuran besar. Pada pola saluran pemasaran II sebesar Rp. 1.000,- untuk ukuran kecil, dan Rp. 2.000,- untuk ukuran sedang dan besar. Pada pola saluran pemasaran III sebesar Rp. 3.000,- untuk ukuran kecil, sedang dan besar. Total keuntungan pemasaran tempe per bungkus pada pola saluran pemasaran I sebesar Rp. 900,- untuk tempe ukuran kecil, Rp. 1.100,- untuk tempe ukuran sedang dan Rp. 1.210,untuk tempe ukuran besar. Pada pola saluran pemasaran II sebesar Rp. 500,- untuk tempe ukuran kecil, Rp. 1.000,- untuk tempe ukuran sedang dan besar. Pada pola saluran pemasaran III sebesar Rp. 1.800,- untuk ukuran tempe kecil, sedang dan besar.
\end{abstract}

Kata Kunci: Agroindustri tempe, lembaga pemasaran, saluran pemasaran

\section{ABSTRACT}

This research was conducted in the City of Palangka Raya. The location of the research was done intentionally (purposive sampling) with the consideration that as the capital city of Central Kalimantan Province, in Palangka Raya City there was a lot of enthusiasm and became the center of tempe agroindustry production. Determination of tempe agroindustry respondents was conducted using the census method (census sampling), which is by taking all tempe agro-industry entrepreneurs (16 entrepreneurs) in Palangka Raya City. Furthermore, the determination of the tempe marketing institutions which includes large wholesalers and retailers is carried out by a snowball sampling method. Data collected in this study are primary data and secondary data. Tempe marketing in Palangka Raya City consists of three 
marketing channels and the marketing institutions involved are wholesalers and retailers. The total marketing costs of tempe per pack in the marketing channel patterns I, II and III are Rp. 0,-, Rp. 500,- and Rp. 1,000,- and also Rp. 1,200,-. The total marketing margin of tempe per pack in the marketing channel pattern I is Rp. 900,-for small sizes, Rp. 1,100,-for medium size and Rp. 1,210,- for large sizes. In the marketing channel pattern II is Rp. 1,000,-for small size, and Rp. 2,000,-for medium and large sizes. In the marketing channel pattern III of Rp. 3,000,-for small, medium and large sizes. The total profit for marketing tempe per pack in the marketing channel pattern I is Rp. 900,- for small tempe, Rp. 1,100,- for medium-sized tempe and Rp. 1,210,- for large tempe. In the marketing channel pattern II is Rp. 500,- for small tempe, Rp. 1,000,-for medium and large tempe. In the marketing channel pattern III of Rp. 1,800,-for small, medium and large sizes tempe.

Keywords: Marketing channel, marketing institution, tempe agroindustry

\section{PENDAHULUAN}

Perkembangan sektor industri di Indonesia, khususnya industri hasil pertanian sangat pesat dalam dasawarsa terakhir, seiring dengan usaha Pemerintah dalam mengembangkan sektor industri ini. Hal ini menjadikan industri hasil pertanian sangat berperan dalam pertumbuhan perekonomian Indonesia, karena sangat menunjang perkembangan sektor pertanian yang masih merupakan penghasilan utama sebagian besar penduduk Indonesia yang merupakan masyarakat agraris (Wicaksono, 2014).

Peranan industri kecil terhadap roda perekonomian suatu negara sangat besar, sistem pemasaran pada industri kecil tersebut mencakup kegiatan produktif yang dilakukan oleh lembaga-lembaga pemasaran yang ada dalam sistem pemasaran industri kecil itu sendiri. Dalam meningkatkan peranan industri kecil, pemasaran sangat perlu karena dapat meningkatkan pendapatan para pengusaha yang ada pada industri kecil. Tingkat produktivitas sistem pemasaran ditentukan oleh tingkat efisiensi dan efektivitas seluruh kegiatan fungsional sistem pemasaran tersebut, yang selanjutnya menentukan kinerja operasi dan proses pemasaran (Ngatno, dkk. 2013).

Salah satu agroindustri yang cukup potensial adalah agroindustri tempe. Pada umumnya tempe berbahan baku kedelai digunakan sebagai lauk-pauk dan sebagai makanan tambahan atau jajanan. Potensi tempe dalam meningkatkan kesehatan dan harganya relatif murah memberikan alternatif pilihan dalam pengadaan makanan bergizi yang dapat dijangkau oleh segala lapisan masyarakat (Sutrisno, 2006). Tujuan utama agroindustri tempe adalah untuk mendapatkan hasil penjualan yang maksimal serta memperoleh keuntungan yang sebesar-besarnya guna memenuhi kebutuhan hidup dan untuk kelangsungan usahanya. Untuk mencapai tujuan tersebut maka pengusaha agroindustri tempe haruslah memasarkan produknya dengan tepat. Peluang pasar tempe yang prospektif dapat mendorong dan memacu pengusaha agroindustri tempe untuk lebih dapat memanfaatkan peluang pasar. Agroindustri tempe akan mengalami peningkatan seiring dengan pertumbuhan jumlah penduduk dan meningkatnya pendapatan, daya beli masyarakat, serta tumbuhnya kesadaran masyarakat akan kecukupan gizi. Salah satu daerah yang cukup berkembang aktivitas agroindustrinya adalah Kota Palangka Raya yang pada umumnya dalam bentuk skala industri kecil atau industri rumah tangga.

Menurut Said dan Intan (2006), sistem pemasaran pertanian adalah suatu kesatuan urutan lembaga-lembaga pemasaran yang melakukan fungsi-fungsi pemasaran untuk memperlancar aliran produk dari produsen hingga konsumsen. 
Sebaliknya memperlancar aliran uang, menambah nilai produk yang tercipta oleh kegiatan produktif yang dilakukan oleh lembaga-lembaga pemasaran dari konsumen akhir produsen awal dalam suatu sistem pemasaran komoditas. Pemasaran mempunyai peranan penting dalam pembangunan ekonomi, hal ini dapat dilihat dalam menciptakan nilai guna dari suatu barang. Nilai guna yang diciptakan terjadi karena tempat, waktu, bentuk dan kepemilikan. Melalui fungsinya, pemasaran memberikan nilai tambah dari suatu barang atau komoditas melalui peningkatan mutu (Wulandari, 2008). Pemasaran produk pertanian seringkali menimbulkan selisih harga yang relatif tinggi antara produsen dengan konsumen. Hal ini dapat disebabkan karena besarnya biaya pemasaran dan keuntungan yang diambil oleh tiap-tiap lembaga pemasaran. Besarnya biaya yang dikeluarkan dan keuntungan yang didapat lembaga pemasaran tersebut akan menimbulkan adanya marjin pemasaran yang besar.

Sistem pemasaran kedelai berkembang karena dipengaruhi oleh perilaku pedagang besar, pedagang kecil maupun pengusaha agroindustri tempe. Beberapa faktor perlu diketahui terkait karakter pelaku perdagangan kedelai (petani, pedagang kecil/besar), faktorfaktor yang mempengaruhi pemasaran seperti kualitas kedelai, harga jual, marjin usaha, dan peran setiap kawasan sentra produksi dalam memasok pasar kedelai. Dengan demikian untuk mengetahui beberapa hal terkait sistem pemasaran bahan baku kedelai dan nilai tambah yang muncul akibat adanya proses penyaluran tempe dari produsen hingga ke konsumen, biaya yang dikeluarkan, keuntungan yang diperoleh lembaga pemasaran tempe, serta marjin pemasaran, maka dalam penelitian ini perlu menganalisis biaya pemasaran, keuntungan dan margin pemasaran tempe di Kota Palangka Raya.

\section{METODE PENELITIAN}

Penelitian ini dilaksanakan di Kota Palangka Raya sebagai ibukota Provinsi Kalimantan Tengah. Pemilihan lokasi penelitian ini dilakukan secara sengaja (purposive sampling) dengan pertimbangan bahwa di Kota Palangka Raya dianggap banyak aktivitas dan menjadi sentra produksi agroindustri tempe.

Penentuan responden agroindustri tempe dilakukan dengan menggunakan metode sensus (sensus sampling), yaitu dengan mengambil seluruh pengusaha agroindustri tempe yang ada di Kota Palangka Raya. Menurut hasil survei lapangan, terdapat 16 agroindustri tempe yang beraktivitas di Kota Palangka Raya. Selanjutnya penentuan lembaga pemasaran tempe yang meliputi pedagang besar dan pedagang pengecer dilakukan dengan metode penelusuran (snowball sampling).

Data yang dikumpulkan dalam penelitian ini adalah data primer dan data sekunder. Data primer diperoleh dari hasil wawancara dengan pengusaha agoindustri tempe, produsen bahan baku kedelai dan lembaga pemasaran yang terlibat dalam pemasaran tempe menggunakan daftar pertanyaan (quisioner). Data sekunder bersumber dari instansi Pemerintah atau pihak lembaga terkait diantaranya Badan Pusat Statistik Provinsi Kalimantan Tengah, Badan Pusat Statistik Kota Palangka Raya, serta Dinas Perindustrian dan Perdagangan Kota Palangka Raya.

Penelitian ini menggunakan metode analisis deskriptif kuantitatif. Untuk menganalisis biaya pemasaran, keuntungan pemasaran dan marjin pemasaran tempe, maka digunakan formulasi sebagai berikut:

$$
\mathrm{BP}=\mathrm{BP}_{1}+\mathrm{BP}_{2}+\ldots \ldots+\mathrm{BPn}
$$

Keterangan:

\begin{tabular}{|c|c|}
\hline BP & $\begin{array}{l}\text { Biaya } \\
\text { tempe }\end{array}$ \\
\hline $\mathrm{BP}_{1}, \mathrm{BP}_{2}, \ldots, \mathrm{BPn}$ & $\begin{array}{l}\text { : Biaya } \\
\text { tiap } \\
\text { pemas }\end{array}$ \\
\hline
\end{tabular}


$\mathrm{KP}=\mathrm{KP}_{1}+\mathrm{Kp}_{2}+\ldots \ldots+\mathrm{KPn}$

Keterangan:

$\begin{array}{ll}\mathrm{KP} & : \begin{array}{l}\text { Keuntungan } \\ \text { pemasaran tempe }\end{array} \\ \mathrm{KP}_{1}, \mathrm{KP}_{2}, \ldots, \mathrm{KPn}: & \text { Keuntungan } \\ & \begin{array}{l}\text { pemasaran tiap } \\ \text { lembaga pemasaran } \\ \text { tempe }\end{array}\end{array}$

$$
\mathrm{MP}=\operatorname{PrK}-\operatorname{PrP}
$$

Keterangan:

MP : Marjin pemasaran tempe

PrK : Harga tempe di tingkat konsumen

PrP : Harga tempe di tingkat produsen

Keterangan:

$$
\mathrm{MP}=\mathrm{BP}+\mathrm{KP}
$$

MP : Marjin pemasaran tempe

$\mathrm{BP}$ : Biaya pemasaran tempe

KP : Keuntungan pemasaran tempe

\section{HASIL DAN PEMBAHASAN}

\section{Lembaga dan Saluran Pemasaran Tempe}

Pemasaran tempe adalah kegiatan penyaluran tempe dari agroindustri tempe baik secara langsung ke konsumen maupun melalui lembaga-lembaga pemasaran. Wilayah pemasaran tempe di Kota Palangka Raya relatif sama antar beberapa agroindustri tempe, yaitu disalurkan di pasar dalam kota atau pasar yang dekat dengan lokasi agroindustri (Pasar Besar dan Pasar Kahayan), di samping ada juga yang disalurkan ke luar kota melalui pedagang besar.

Lembaga pemasaran tempe meliputi agroindustri tempe dan pedagang tempe (pedagang besar/pedagang pengecer). Agroindustri melaksanakan kegiatan pengolahan kedelai hingga menjadi tempe dan sekaligus melakukan kegiatan pemasaran. Proses pemasaran tempe oleh agroindustri tempe dapat melalui beberapa cara, yakni: (1). Menjual langsung ke konsumen akhir; (2). Menjual melalui pedagang pengumpul; dan (3) Menjual melalui pengecer. Agroindustri tempe menjual tempe berukuran kecil dengan harga rata-rata Rp. 2.000,- per bungkus, berukuran sedang dengan harga rata-rata Rp. 2.500,- per bungkus, dan untuk tempe berukuran besar dijual dengan harga rata-rata Rp. 3.000,- per bungkus.

Pedagang besar adalah pedagang yang membeli tempe dari agroindustri tempe dan setelah terkumpul kemudian menjualnya ke pedagang pengecer. Pedagang besar biasanya berdomisili di luar kota sehingga keberadaannya menjalin hubungan baik dengan pedagang pengecer yang ada di luar kota. Pembelian tempe dari agroindustri tempe oleh pedagang besar dilakukan dengan dua cara, yakni: (1). Pedagang besar langsung membeli tempe dari agroindustri tempe yang berada di luar pasar; dan (2). Pedagang besar membeli tempe dari agroindustri tempe yang ada di Pasar Besar Kota Palangka Raya. Semua biaya pengangkutan ditanggung oleh pedagang besar. Selanjutnya pedagang besar menjual tempe berukuran kecil dengan harga Rp. 4.000,per bungkus, berukuran sedang dengan harga Rp. 5.000,- per bungkus, dan berukuran besar dengan harga Rp. 6.000,per bungkus.

Pedagang pengecer di Kota Palangka Raya menjual tempe langsung kepada konsumen dalam jumlah yang relatif sedikit. Pedagang pengecer tempe banyak dijumpai di pasar-pasar tradisional dan di sekitar perumahan warga yang ada di Kota Palangka Raya. Pedagang pengecer menjual tempe dengan berbagai macam harga. Harga tempe berukuran kecil sebesar Rp. 3.000,- per bungkus, untuk tempe berukuran sedang dijual dengan harga Rp. 5.000,- per bungkus, dan untuk tempe yang berukuran besar dijual dengan harga Rp. 6000,- per bungkus.

Saluran pemasaran merupakan aliran penyaluran tempe dari lembagalembaga pemasaran ke konsumen. Berdasarkan hasil penelitian, diketahui pola saluran pemasaran tempe di Kota Palangka Raya seperti terlihat pada Gambar 1 berikut. 


$\begin{array}{llll}\mathrm{I}=\begin{array}{l}\text { Agroindustri } \\ \text { Tempe }\end{array} & & \text { Konsumen } \\ \mathrm{II}=\begin{array}{l}\text { Agroindustri } \\ \text { Tempe }\end{array} & & \begin{array}{l}\text { Pedagang } \\ \text { Pengecer }\end{array} & \text { Konsumen } \\ \text { III }=\begin{array}{l}\text { Agroindustri } \\ \text { Tempe }\end{array} & \begin{array}{l}\text { Pedagang } \\ \text { Besar }\end{array} & \begin{array}{l}\text { Pedagang } \\ \text { Pengecer }\end{array} & \text { Konsumen }\end{array}$

Gambar 1. Pola Saluran Pemasaran Tempe di Kota Palangka Raya

Sumber: Hasil Analisis Data Primer

Berdasarkan Gambar 1, diketahui bahwa saluran pemasaran tempe yang ada di Kota Palangka Raya terdiri dari 3 pola saluran, yakni: (1) Saluran I, Agroindustri tempe menjual produknya kepada konsumen dengan cara konsumen mendatangi secara langsung ke tempat industri pengolahan tempe. Tidak ada lembaga pemasaan yang terlibat dalam saluran pemasaran; (2). Saluran II, agroindustri tempe menjual produknya ke pedagang pengecer yang berada di sekitar agroindustri, kemudian pedagang pengecer menjualnya kepada konsumen. Lembaga pemasaran yang terlibat adalah pedagang pengecer; dan (3). Saluran III, agroindustri tempe menjual produknya ke pedagang besar yang ada di Pasar Besar Kota Palangka Raya, kemudian pedagang besar menjualnya lagi ke pedagang pengecer yang berada di luar Kota Palangka Raya seperti Kuala Kurun, Kasongan, Tumbang Talaken, Puruk Cahu. Selanjutnya pedagang pengecer menjualnya ke konsumen. Lembaga pemasaran yang terlibat adalah pedagang besar dan pedagang pengecer.

\section{Fungsi Pemasaran Tempe}

Fungsi pemasaran meliputi fungsi pertukaran terdiri dari fungsi pembelian dan penjualan, fungsi fisik terdiri dari fungsi pengangkutan, penyimpanan dan pengemasan, serta fungsi fasilitas terdiri dari sortasi, grading, informasi pasar, pembiayaan, dan penanggungan risiko. Lebih jelasnya fungsi pemasaran tempe di Kota Palangka Raya seperti terlihat pada Tabel 1.

Tabel 1. Fungsi Pemasaran Tempe di Kota Palangka Raya

\begin{tabular}{|c|c|c|c|c|c|}
\hline $\begin{array}{c}\text { Fungsi } \\
\text { Pemasaran }\end{array}$ & Aktivitas & $\begin{array}{l}\text { Agroindustri } \\
\text { Tempe }\end{array}$ & $\begin{array}{c}\text { Pedagang } \\
\text { Besar }\end{array}$ & $\begin{array}{l}\text { Pedagang } \\
\text { Pengecer }\end{array}$ & Konsumen \\
\hline \multirow[t]{2}{*}{ Pertukaran } & Pembelian & $\sqrt{1}$ & $\sqrt{ }$ & $\sqrt{1}$ & $\sqrt{ }$ \\
\hline & Penjualan & $\sqrt{ }$ & $\sqrt{ }$ & $\sqrt{ }$ & - \\
\hline \multirow[t]{3}{*}{ Fisik } & Pengangkutan & $\sqrt{ }$ & $\sqrt{ }$ & - & - \\
\hline & Penyimpanan & $\sqrt{ }$ & $\sqrt{ }$ & $\sqrt{ }$ & - \\
\hline & Pengemasan & $\sqrt{ }$ & - & - & - \\
\hline \multirow[t]{5}{*}{ Fasilitas } & Sortasi & $\sqrt{ }$ & - & - & - \\
\hline & Grading & - & - & - & - \\
\hline & Informasi pasar & $\sqrt{ }$ & $\sqrt{ }$ & $\sqrt{ }$ & $\sqrt{ }$ \\
\hline & Pembiayaan & $\sqrt{ }$ & $\sqrt{ }$ & $\sqrt{ }$ & - \\
\hline & Resiko & $\sqrt{ }$ & $\sqrt{ }$ & $\sqrt{ }$ & - \\
\hline
\end{tabular}

Sumber: Hasil Analisis Data Primer. 
Fungsi pemasaran yang dilakukan oleh agroindustri tempe meliputi: fungsi pertukaran, fungsi fisik dan fungsi fasilitas. Dalam fungsi pertukaran, agroindustri tempe melakukan pembelian bahan baku kedelai dan bahan lainnya untuk mengolah kedelai hingga menjadi tempe yang siap dijual. Agroindustri tempe melakukan fungsi fisik yaitu fungsi pengangkutan dan pengemasan, dimana pengemasan tempe dengan menggunakan plastik dan daun pisang. Selanjutnya fungsi fasilitas yang dilakukan oleh agroindustri tempe yaitu fungsi sortasi yang dilakukan ketika mencuci kedelai, memisahkan kedelai dari sisa-sisa kotoran atau kulit kedelai yang masih ada. Fungsi informasi pasar dilakukan agroindustri tempe dengan menerima informasi mengenai jumlah tempe yang akan dipesan/disalurkan oleh lembaga-lembaga pemasaran. Fungsi penanggungan resiko yang dilakukan oleh agroindustri tempe adalah apabila tempe rusak atau ada cacat maka tempe dijual, namun akan menggantinya dengan tempe yang bagus.

Fungsi pemasaran yang dilakukan oleh pedagang besar tempe, meliputi: fungsi pertukaran, fungsi fisik dan fungsi fasilitas. Dalam fungsi pertukaran, pedagang besar melakukan pembelian tempe dari agroindustri tempe, kemudian disalurkan/dijual ke pedagang pengecer. Pedagang besar juga melakukan fungsi fisik yaitu fungsi pengangkutan, dengan menyalurkan tempe sampai ke luar daerah Kota Palangka Raya. Fungsi informasi yang dilakukan oleh pedagang besar dengan menerima informasi mengenai jumlah kebutuhan tempe yang diminta/djual oleh pedagang pengecer. Fungsi penanggungan resiko yang dilakukan pedagang tempe adalah apabila tempe rusak atau cacat maka tempe tidak bisa dijual atau diganti dengan tempe yang baru.

Fungsi pemasaran oleh pedagang pengecer tempe, meliputi: fungsi pertukaran, fungsi fisik dan fungsi fasilitas. Fungsi pertukaran oleh pedagang pengecer dengan melakukan pembelian tempe dari pedagang besar, kemudian tempe disalurkan/dijual kembali ke konsumen akhir. Pedagang pengecer biasanya adalah pedagang sayur mayur yang keberadaannya di sekitar lingkungan konsumen. Pedagang pengecer juga melakukan fungsi fisik yaitu fungsi penyimpanan. Sementara fungsi informasi pasar yang dilakukan oleh pedagang pengecer dengan menerima informasi mengenai jumlah pesanan tempe yang dibutuhkan oleh konsumen. Fungsi penanggungan resiko yang dilakukan oleh pedagang pengecer adalah apabila tempe mengalami kerusakan, maka akan diganti dengan yang baru.

Fungsi pemasaran yang dilakukan oleh konsumen adalah fungsi pertukaran dan fungsi fasilitas. Fungsi pertukaran, konsumen membeli tempe untuk dikonsumsi. Konsumsi tempe dilakukan dengan cara diolah terlebih dahulu untuk dijadikan lauk-pauk atau dijadikan bahan tambahan dalam masakan. Semua proses pembiayaan berasal dari pembayaran konsumen terhadap produk tempe yang dibeli, sehingga informasi tentang kebutuhan/keinginan konsumen merupakan penentu arah dari proses keberlangsungan agroindustri tempe.

\section{Biaya, Keuntungan dan Marjin Pemasaran Tempe}

Perbedaan pola saluran dan panjang pendeknya saluran pemasaran akan mempengaruhi tingkat harga, bagian keuntungan dan biaya serta margin pemasaran yang diterima setiap pelaku pemasaran (Yusuf, 2011). Besarnya biaya, keuntungan dan marjin pemasaran tempe pada pola saluran pemasaran I di Kota Palangka Raya dapat dilihat seperti pada Tabel 2. 
Tabel 2. Biaya, Keuntungan dan Marjin Pemasaran Tempe pada Pola Saluran I di Kota Palangka Raya

\begin{tabular}{|c|c|c|c|}
\hline \multirow[b]{2}{*}{ Uraian } & \multicolumn{3}{|c|}{ Ukuran Kemasan Tempe } \\
\hline & $\begin{array}{c}\text { Kecil } \\
\text { (Rp) }\end{array}$ & $\begin{array}{c}\text { Sedang } \\
\text { (Rp) }\end{array}$ & $\begin{array}{l}\text { Besar } \\
\text { (Rp) }\end{array}$ \\
\hline \multicolumn{4}{|l|}{ 1. Agroindustri tempe } \\
\hline 1. Biaya bahan baku & 616 & 1.016 & 1.616 \\
\hline \multicolumn{4}{|l|}{ 2. Biaya pengolahan: } \\
\hline a. Penggilingan & 138 & 238 & 382 \\
\hline b. Peragian & 124 & 224 & 278 \\
\hline c. Tenaga Kerja & 222 & 422 & 514 \\
\hline Jumlah biaya pengolahan & 484 & 884 & 1.174 \\
\hline 3. Total biaya produksi & 1.110 & 1.900 & 2.790 \\
\hline 4. Keuntungan & 900 & 1.100 & 1.210 \\
\hline 5. Harga jual tempe & 2.000 & 3.000 & 4.000 \\
\hline \multicolumn{4}{|l|}{ 2. Konsumen } \\
\hline Harga beli tempe & 2.000 & 3.000 & 4.000 \\
\hline Total biaya pemasaran & - & - & - \\
\hline Total keuntungan pemasaran & 900 & 1.100 & 1.210 \\
\hline Total marjin pemasaran & 900 & 1.100 & 1.210 \\
\hline
\end{tabular}

Sumber: Hasil Analisis Data Primer.

Berdasarkan Tabel 2, diketahui bahwa dalam proses pengolahan tempe yang dilakukan oleh agroindustri tempe, biaya-biaya yang dikeluarkan antara lain biaya bahan baku dan biaya pengolahan yang dibebankan menurut jenis ukuran kemasan tempe. Harga jual tempe oleh agroindustri tempe dan harga beli tempe oleh konsumen pada pola saluran pemasaran I sama, yakni untuk ukuran kecil sebesar Rp. 2.000,-/bungkus, ukuran sedang sebesar Rp. 3.000,-/bungkus dan tempe ukuran besar dengan harga sebesar Rp. 4.000,-/bungkus. Agroindustri tempe pada pola saluran pemasaran I sudah memiliki pelanggan/konsumen tetap, sehingga agroindustri tempe lebih suka memilih pola saluran ini. Alasannya lebih praktis karena bisa menjual secara langsung produk tempe ke konsumen tanpa mengeluarkan biaya pemasaran. Konsumen tempe pada pola saluran pemasaran I ini adalah para konsumen yang datang membeli langsung dalam jumlah besar seperti rumah/warung makan, pedagang gorengan dan untuk keperluan konsumsi para konsumen yang ada di sekitar agroindustri tersebut.

Pola saluran pemasaran II pada pemasaran tempe di Kota Palangka Raya terdapat satu lembaga pemasaran, yakni pedagang pengecer. Besarnya biaya, keuntungan dan marjin pemasaran tempe pada saluran pemasaran II di Kota Palangka Raya dapat dilihat lengkap seperti pada Tabel 3.

Tabel 3. Biaya, Keuntungan dan Marjin Pemasaran Tempe pada Pola Saluran II di Kota Palangka Raya

\begin{tabular}{lccc}
\hline & \multicolumn{3}{c}{ Ukuran Kemasan Tempe } \\
\cline { 2 - 4 } & $\begin{array}{c}\text { Kecil } \\
(\mathrm{Rp})\end{array}$ & $\begin{array}{c}\text { Sedang } \\
(\mathrm{Rp})\end{array}$ & $\begin{array}{c}\text { Besar } \\
(\mathrm{Rp})\end{array}$ \\
\hline $\begin{array}{l}\text { 1. Agroindustri Tempe } \\
\text { 1. Biaya bahan baku } \\
\text { 2. Biaya pengolahan: }\end{array}$ & 616 & 1.016 & 1.616
\end{tabular}




\begin{tabular}{lrrr} 
a. Perebusan & 138 & 238 & 382 \\
b. Penggilingan & 124 & 224 & 278 \\
c. Tenaga Kerja & 222 & 422 & 514 \\
Jumlah biaya pengolahan & 484 & 884 & 1.174 \\
3. Total biaya produksi & 1.110 & 1.900 & 2.790 \\
4. Keuntungan & 900 & 1.100 & 1.210 \\
5. Harga jual tempe & 2.000 & 3.000 & 4.000 \\
\hline 2. Pedagang Pengecer & & & \\
1. Harga beli tempe & 2.000 & 3.000 & 4.000 \\
2. Biaya pemasaran & & & \\
$\quad$ a. Transportasi & 320 & 470 & 470 \\
b. Pengangkutan & 140 & 245 & 245 \\
$\quad$ c. Retribusi & 200 & 285 & 285 \\
$\quad$ Jumlah biaya pemasaran & 500 & 1.000 & 1.000 \\
3. Marjin pemasaran & 1.000 & 2.000 & 2.000 \\
4. Keuntungan & 500 & 1.000 & 1.000 \\
5. Harga jual tempe & 3.000 & 5.000 & 6.000 \\
\hline 3. Konsumen & & & \\
Harga beli tempe & 3.000 & 5.000 & 6.000 \\
\hline Total biaya pemasaran & 500 & 1.000 & 1.000 \\
\hline Total keuntungan pemasaran & 500 & 1.000 & 1.000 \\
\hline Total marjin pemasaran & 1.000 & 2.000 & 2.000 \\
\hline Subr. Hasil Anasis Dat Primer
\end{tabular}

Sumber: Hasil Analisis Data Primer.

Berdasarkan pada Tabel 3, diketahui bahwa lembaga pemasaran yang terlibat pada pola saluran II hanya ada satu, yaitu pedagang pengecer. Berawal dari pedagang pengecer, tempe langsung dipasarkan kepada konsumen akhir. Pada pola saluran pemasaran II ini, harga beli pedagang pengecer dari agroindustri untuk tempe ukuran kecil sebesar Rp. 2.000,/bungkus, untuk tempe ukuran sedang sebesar Rp. 3.000,-/bungkus, dan untuk tempe ukuran besar sebesar Rp. 4.000,/bungkus. Pedagang pengecer mengeluarkan biaya-biaya untuk pemasaran seperti untuk biaya transportasi, biaya pengemasan dan biaya retribusi. Selanjutnya harga jual pedagang pengecer pada pola saluran pemasaran II sama dengan harga beli konsumen, yakni untuk tempe ukuran kecil sebesar Rp. 3.000,/bungkus, tempe ukuran sedang sebesar Rp. 5.000,-/bungkus, dan untuk tempe ukuran besar sebesar Rp. 6.000,-/bungkus.

Pola saluran pemasaran II adalah pola saluran pemasaran yang paling banyak digunakan oleh agroindustri tempe di Kota Palangka Raya. Pada umumnya agroindustri tempe di Pasar Besar Kota Palangka Raya sudah memiliki langganan pedagang pengecer yang tetap sebagai penyalur tempe. Peran pedagang pengecer sangat diperlukan dalam penyaluran tempe hingga sampai ke tangan konsumen. Apabila tempe tidak semua terjual pada hari pertama, maka akan disimpan di lemari pendingin supaya tidak rusak (basi) dan akan dijual lagi pada hari berikutnya dengan harga yang sama dengan sebelumnya. Total keuntungan yang diperoleh pedagang pengecer pada pola saluran II ini cukup tinggi, karena di sisi lain juga menanggung resiko tinggi apabila tempe tidak laku lebih dari 4 hari.

Sementara pola saluran pemasaran III merupakan saluran yang terakhir pada pemasaran tempe. Besarnya biaya, keuntungan dan marjin pemasaran tempe pada pola saluran pemasaran III di Kota Palangka Raya dapat dilihat pada Tabel 4. 
Tabel 4. Biaya, Keuntungan dan Marjin Pemasaran Tempe pada Pola Saluran III di Kota Palangka Raya

\begin{tabular}{|c|c|c|c|}
\hline \multirow[b]{2}{*}{ Uraian } & \multicolumn{3}{|c|}{ Ukuran Kemasan Tempe } \\
\hline & $\begin{array}{c}\text { Kecil } \\
\text { (Rp) }\end{array}$ & $\begin{array}{c}\text { Sedang } \\
(\mathrm{Rp})\end{array}$ & $\begin{array}{c}\text { Besar } \\
\text { (Rp) }\end{array}$ \\
\hline \multicolumn{4}{|l|}{ 1. Agroindustri Tempe } \\
\hline 1. Biaya bahan baku & 616 & 1.016 & 1.616 \\
\hline \multicolumn{4}{|l|}{ 2. Biaya Pengolahan } \\
\hline a. Perebusan & 138 & 238 & 382 \\
\hline b. Penggilingan & 124 & 224 & 278 \\
\hline c. Tenaga Kerja & 222 & 422 & 514 \\
\hline Jumlah biaya pengolahan & 484 & 884 & 1.174 \\
\hline 3. Total biaya produksi & 1.110 & 1.900 & 2.790 \\
\hline 4. Keuntungan & 900 & 1.100 & 1.210 \\
\hline 5. Harga jual tempe & 2.000 & 3.000 & 4.000 \\
\hline \multicolumn{4}{|l|}{ 2. Pedagang Besar } \\
\hline 1. Harga beli tempe & 2.000 & 3.000 & 4.000 \\
\hline \multicolumn{4}{|l|}{ 2. Biaya pemasaran } \\
\hline a. Transportasi & 600 & 600 & 600 \\
\hline b. Pengangkutan & 138 & 138 & 138 \\
\hline c. Retribusi & 262 & 262 & 262 \\
\hline Jumlah biaya pemasaran & 1.000 & 1.000 & 1.000 \\
\hline 3. Marjin pemasaran & 2.000 & 2.000 & 2.000 \\
\hline 4. Keuntungan & 1.000 & 1.000 & 1.000 \\
\hline 5. Harga jual tempe & 4.000 & 5.000 & 6.000 \\
\hline \multicolumn{4}{|l|}{ 3. Pedagang Pengecer } \\
\hline 1. Harga beli tempe & 4.000 & 5.000 & 6.000 \\
\hline \multicolumn{4}{|l|}{ 2. Biaya pemasaran } \\
\hline a. Transportasi & 0 & 0 & 0 \\
\hline b. Pengangkutan & 0 & 0 & 0 \\
\hline c. Retribusi & 200 & 200 & 200 \\
\hline Jumlah biaya pemasaran & 200 & 200 & 200 \\
\hline 3. Marjin pemasaran & 1.000 & 1.000 & 1.000 \\
\hline 4. Keuntungan & 800 & 800 & 800 \\
\hline 5. Harga jual tempe & 5.000 & 6.000 & 7.000 \\
\hline \multicolumn{4}{|l|}{ 4. Konsumen } \\
\hline Harga beli konsumen & 5.000 & 6.000 & 7.000 \\
\hline \multirow{3}{*}{$\begin{array}{ll}5 . & \text { Total Biaya pemasaran } \\
& \text { Total keuntungan pemasaran } \\
\text { Total marjin pemasaran }\end{array}$} & 1.200 & 1.200 & 1.200 \\
\hline & 1.800 & 1.800 & 1.800 \\
\hline & 3.000 & 3.000 & 3.000 \\
\hline
\end{tabular}

Sumber: Hasil Analisis Data Primer.

Berdasarkan Tabel 4, diketahui bahwa pada pola saluran pemasaran III terdapat dua lembaga pemasaran yaitu pedagang besar dan pedagang pengecer. Harga jual tempe oleh agroindustri tempe sama dengan harga beli tempe oleh pedagang besar, yakni sebesar Rp. 2.000,- /bungkus untuk tempe berukuran kecil, untuk ukuran sedang sebesar Rp. 3.000,/bungkus dan untuk tempe berukuran besar sebesar Rp. 4.000,-/bungkus.

Pedagang besar mengeluarkan biaya-biaya untuk pemasaran seperti biaya transportasi, biaya pengangkutan dan biaya 
retribusi sebesar Rp. 1.000,-/bungkus, sehingga marjin pemasaran sebesar $\mathrm{Rp}$. 2.000/bungkus dan keuntungan yang diterima oleh pedagang besar sebesar Rp. $1.000,-/$ bungkus. Berikutnya harga jual tempe oleh pedagang besar sama dengan harga beli tempe oleh pedagang pengecer luar kota, yakni untuk ukuran tempe kecil sebesar Rp. 4.000,-/bungkus, untuk tempe ukuran sedang sebesar Rp. 5.000,/bungkus, dan untuk tempe ukuran besar sebesar Rp. 6.000,-/bungkus.

Pada pola saluran III ini, harga jual tempe oleh pedagang pengecer yang berada di luar Kota Palangka Raya sama dengan harga beli tempe oleh konsumen, yakni untuk tempe berukuran kecil sebesar Rp. 5.000,-/bungkus, untuk tempe berukuran sedang sebesar Rp. 6.000,/bungkus dan untuk tempe berukuran besar sebesar Rp. 7.000,-/bungkus. Pada pola saluran pemasaran III, pedagang pengecer mengeluarkan biaya retribusi sebesar $\mathrm{Rp}$. 200,-/bungkus, sehingga marjin pemasaran sebesar Rp. 1.000,-/bungkus dan keuntungan yang diterima oleh pedagang pengecer sebesar Rp. 800,-/bungkus.

Total marjin pemasaran tempe tertinggi terdapat pada pola saluran pemasaran III yaitu sebesar Rp. 3.000,/bungkus. Hal ini disebabkan karena lokasi pemasaran tempe relatif lebih jauh yang berada di luar Kota Palangka Raya, sehingga menjadikan pedagang besar dan pedagang pengecer mengambil keuntungan yang lebih tinggi.

\section{KESIMPULAN DAN SARAN}

\section{Kesimpulan}

1. Pemasaran tempe di Kota Palangka Raya terdiri dari tiga saluran pemasaran dan lembaga pemasaran yang terlibat adalah pedagang besar dan pedagang pengecer.

2. Total biaya pemasaran tempe per bungkus pada pola saluran pemasaran I, II dan III masing-masing sebesar Rp. 0,-, Rp. 500,- dan Rp. 1.000,-, serta Rp. $1.200,-$.
3. Total marjin pemasaran tempe per bungkus pada pola saluran pemasaran I sebesar Rp. 900,- untuk ukuran kecil, Rp. 1.100,- untuk ukuran sedang dan Rp. 1.210,- untuk ukuran besar. Pada pola saluran pemasaran II sebesar Rp. 1.000,- untuk ukuran kecil, dan Rp. 2.000,- untuk ukuran sedang dan besar. Pada pola saluran pemasaran III sebesar Rp. 3.000,- untuk ukuran kecil, sedang dan besar.

4. Total keuntungan pemasaran tempe per bungkus pada pola saluran pemasaran I sebesar Rp. 900,- untuk tempe ukuran kecil, Rp. 1.100,- untuk tempe ukuran sedang dan Rp. 1.210,- untuk tempe ukuran besar. Pada pola saluran pemasaran II sebesar Rp. 500,- untuk tempe ukuran kecil, Rp. 1.000,- untuk tempe ukuran sedang dan besar. Pada pola saluran pemasaran III sebesar Rp. 1.800,- untuk ukuran tempe kecil, sedang dan besar.

\section{Saran}

1. Kepada para pengusaha agroindustri tempe di Kota Palangka Raya yang ingin meningkatkan pendapatan/keuntungan, sebaiknya lebih aktif dan produktif dalam mencari peluang pasar dan diharapkan dapat memperpendek saluran pemasaran tempe dengan langsung kepada konsumen akhir, sehingga dapat menekan biaya pemasaran.

2. Kepada Pemerintah Kota Palangka Raya melalui dinas/instansi terkait agar lebih proaktif dalam mengawasi harga bahan baku kedelai yang relatif tinggi dengan menetapkan harga dasar kedelai yang sesuai, sehingga aktivitas agroindustri tempe tetap berjalan dan tidak mengalami kerugian.

\section{DAFTAR PUSTAKA}

Ngatno, Azhar, S., \& Sepfera, M. (2013). Analisis Kinerja Saluran Pemasaran Industri Kecil. Studi Kasus Pengusaha Tahu Mekar Sari di 
Kelurahan Pematang Kandis Kecamatan Bangko Kabupaten Merangin. Jurnal Agri Sains, 1 (1), 1-8. Fakultas Pertanian Universitas Muara Bungo, Jambi. Retrieved from

http://docplayer.info/72012990-

Volume-1-no-1jurnal-agri-

sains.html

Said, E. G. dan Intan, A. H. (2006). Manajemen Agribisnis. Jakarta: Ghalia Indonesia.

Sutrisno, E. (2006). Studi Profil Industri Tempe Berdasarkan Tingkat Kesuksesan. Skripsi. Fakultas Teknologi Pertanian, Institut Pertanian Bogor. Bogor. Retrieved from

https://repository.ipb.ac.id/bitstrea $\mathrm{m} /$ handle/123456789/3663/F06esu. pdf;jsessionid=1AE8A7957432AF 9B5491F68D75593CDB?sequence $=4$

Wicaksono, T. H. (2014). Analisis Variabel-Variabel yang Mempengaruhi Jumlah Produksi pada Industri Kecil Keripik Tempe di Kota Malang (Studi Kasus pada Sentra Industri Keripik Tempe Sanan Kota Malang). Jurnal Ilmiah Mahasiswa FEB UB, 2 (2), Skripsi. Jurusan Ilmu Ekonomi. Fakultas Ekonomi dan Bisnis. Universitas Brawijaya. Malang. Retrieved from https://jimfeb.ub.ac.id/index.php/ji mfeb/article/view/1332

Wulandari. (2008). Analisis Pemasaran Tahu di Kecamatan Kartasura Kabupaten Sukoharjo. Skripsi. Fakultas Pertanian. Universitas Sebelas Maret. Surakarta. Retrieved from https://eprints.uns.ac.id/2113/1/763 71507200903191.pdf

Yusuf. (2011). Analisis Produksi dan Pemasaran Dalam Kerangka (Supply Chain Management) Jeruk Keprok Soe di Kabupaten Timor Tengah Selatan. Disertasi. Program
Pascasarjana Fakultas Pertanian. Universitas Gadjah Mada. Yogyakarta. Retrieved from https://repository.ipb.ac.id/bitstrea m/handle/123456789/53533/2011d ad.pdf?sequence $=1$ 